Blucher Design Proceedings Dezembro de 2014, Numero 5, Volume 1

\title{
Design History and Design Studies in an ever changing cultural complex
}

\begin{abstract}
We sustain the thesis that Design is part of the historical complex of each age, and as such Design History and Design Studies must reflect each epoch's social dynamics, and can not and should not be reduced to a single attitude and posture towards the rationalization and practice of Design.
\end{abstract}

\section{Keywords}

design history, design studies, cultural and civilization complex

\section{Introduction}

In order to make Design History and Design Studies comprehensible we will set - as social and cultural background - the expression of the expectations, aesthetical and ethical values of the dominant social and individual behaviour throughout different cultural frameworks in which Design activities occur.

Within this framework, this professional activity became grounded as a response to ever growing demands within the cultural complex 1 in deep and permanent transformation. 
'The ensemble of human expression that in each period converges into a certain culture makes up the cultural complex of that moment in time.

\section{The cultural and civilization complex: periods of coherence, transition and desegregation}

Based on the notion of cultural complex', we can put forward the hypothesis that such complex presents at different periods different degrees of coherence. Periods of high coherence are exactly those deserving of an appellation.

Concerning Design Studies, it is possible to start delving into the evolution of the cultural paradigm from the beginning of the 2oth century.

\subsection{The ambiguous and transient start of the twentieth century}

The century started in a context of apparent security, but the signs of upheaval were already there: social tensions that surfaced with the turn of the century revolutions; the emergence of economic imperialism and conflicts; the inner dynamic of scientific and philosophical thinking with novel foundational quests and ruptures.

The great questioning of validity of the «certainties» at the late 19th century gave rise to a search for new paths, new dogmas, new principles. It also begot clashes and antagonisms between them. This creates an overall impression of «syncretism» where everything is valid, where everything can be sustained and defended. This syncretism is met by a generalized feeling of insecurity and stirs backlashes manifested in fundamentalist and fanatical attitudes - a widespread response to a complex, uncertain and difficult to explain world (Fragoso, 2012).

Understanding social and economical change inevitably requires explaining the interplay between technology as an engine for change and its cultural and social setting.

The transition between the 19th and 2oth century closed a cycle that Lewis Mumford (1934) called the "paleo-technical era". Cast Iron, coal and the steam engine were the catalysts of deep social and economical transformations: the development of a system marked by the triumph of the second industrial revolution, justified for the sake of efficiency fierce industrial competition and rising social injustices.

Triumphant bourgeois society revelling "in the advance of science, knowledge, education as well as technological material and moral progress" (Hobsbawm, 2002, p.18) was undermined by a malaise that would determine its dismissal.

However, social and cultural mores were still dominated by the tastes of this class that aspired to recreate visual themes and forms - some medieval other exotic - with modern materials and technology. The obvious discrepancy in many areas between established tastes and technical possibilities made visible the conflict between the aesthetical and the technological.

The years just before the First World War, la Belle Époque, disguised a growing malaise through exuberant expectations and behaviour. Seemingly there was a period dominated by the joy of life and vitality. Europe symbolized progress, but it was Parisian life that reflected the Zeitgeist.

It was around this time that the engineer made its appearance as a social hero and mark of progress. It is interesting to point out that the purity of the engineering works was dressed up by revivalist ornament that referred to past historical periods. There was a proliferation of industrial pastiche in opposition to the true function of objects, faked 
materials and techniques trying to copy the old².

The refusal of both the utilitarian aesthetic of the engineer and inspiration in the past styles, led to look for inspiration in the forms of nature, to a return to «fluidity of impression of movement», to a Japanese minimalist style. This style - Art Nouveau - was brief in time but left a deep impact on fashion and society of the 1900's?.

The development of lithography allowed for an expansion of the scope of the graphical arts, and the appearance of advertising agencies that produced «artistic posters», a new form of advertising of growing impact due to the large scale possibilities for the dissemination of information.

Humanity faced a change in the cultural paradigm where everything was coming into question, largely moved by the impact of new technologies: electricity and the internal combustion engine. These were the bases of what Mumford (1934) called the "neotechnical era".

\subsection{The change of cultural paradigm}

In parallel to what happened in other domains, the political and social context also generated impulses to counter the social conservatism. The Great War and the Soviet Revolution altered the established order between great powers and fed revolutionary fervour world wide.

All arts were means by which this social change was made visible. The revolutionary experiences developed by Picasso, Matisse and Brancusi question and reject the legacy of conventional representation. Different movements and trends appeared in quick succession - cubism, abstractionism, futurism...

Architecture abandoned the historicist, ornamental and revivalist forms, and aimed at responding in a rational way to new ways of life and work. Rationalism, functionalism and organicism pointed towards a new aesthetical path4, allowed by the possibilities of the new materials, reinforced concrete and steel.

After the brief Belle Époque moment, the zoth century entered into the «modern life» era characterized by the astonishing changes that scientific and technological advances allowed, for instances new customs impacted on daily life.

\subsection{The rise of social and cultural malaise}

The last quarter of the 2oth century witnessed a new era characterized by the application of information to daily life, to production and scientific research, that Martins Barata (2004) called the "info-technical" period that is at the core of modern telecommunications, television, remote-control, remote detection.

Hobsbawm (2002, p. 395) considers that the history of the twenty years following 1973, "is that of a world that has lost references and slipped into instability and crisis (...). In the non-communist areas of the World, the global crisis was not recognized or even accepted until one part of the world - the USSR and Eastern Europe - had completely collapsed".

According to Steiner (2006, p.43), Europe "had a premonition that it would one day meet ruin, under the paradoxical weight of its deeds and the complexity without match of

\footnotetext{
Already in the second half of the 19th century and in response to this crisis of aesthetics, in England - the country that pioneered the industrial revolution - the Arts and Crafts movements and their leader William Morris criticized industrial production proposing a defence of the artisan; a defence of the culture of the object; the relation of complementarity between architecture and interiors, and denying elites the exclusive domain of the arts. Morris disciples went further accepting the use of machinery; a turning point between a romantic attitude of repulsion of industrialization and the acceptance of the contemporary means of production.
}

\footnotetext{
${ }^{3}$ Art Nouveau, while influenced by Arts and Crafts namely in the combination structure/decoration, moved away from the artisanal aspects by establishing an alliance between art and technology, with a very strong theoretical reflection on the function of objects. It is in this alliance between art and industry that 2oth century design begins.

${ }_{4}$ The functionalist thought that coalesced around the Bauhaus, evolved to high quality and economical products - «Good Design»»
} parameters. 
5 Until the eighties, while forms were not self-contained as they were relatively stable, one could assign them to «one epoch». With post-modernism different aesthetical tendencies - often very short lived - co-exist in a landscaped marked my eclecticism.

\footnotetext{
5 The historical and social process of dissemination has a new expression with the «Global Village» phenomenon. influences flow from everywhere and become accessible to all. The «contagion through proximitys paradigm of dissemination has changed because the world has «shrank». But it is not only the concept of «space» that changed; also the notion of «time» has been altered due to acceleration.
}

its History. Two World Wars - actually two European Civil Wars - led that intimation to a boiling point".

The uncertainty of the Zeitgeist shows up in post-modern attitudes ${ }^{5}$ and in the emergency of a sceptical and critical «deconstructivism». Generalized conflict at a global scale, typified in a «clash of civilizations», overlaps a world wide diffusion of economic, financial and corporate structures under the vague label of «globalization».

At the root of this cultural complex are the new technologies, namely telecommunication and computer science. In this ongoing venture, technology must accompany the Ideas that will act at every moment of history. These are - for instance the development of logics with multiple truth-values incorporating uncertainty, molecular biology, genetics and mathematics. Even the arts navigate towards the growing emergence of the notion of complexity.

An understanding of the cultural nature of technologies presupposes knowledge of human processing of information. Below, we stress some of the ideas behind Knowing, Feeling and Doing.

The paths of knowledge construction, invention and innovation are not linear. They are cultural processes that presuppose reflection, a power of synthesis and analysis, a capacity of relating, of finding nexus between phenomena. However, progress is only achieved by the dissemination of knowledge through different modes. The ages of change and progress are those where knowledge becomes accessible and is spread throughout the whole of a society that demands it, uses it and cultivates it adding to and reconstructing the common cultural legacy. Dissemination operates through different channels. Among these is contagion through proximity: one learns by watching others do and is influenced, either by doing differently and comparing stances and outcomes. Other means are actions observed through media channels.

Still, highly original and innovative knowledge - ideas with a very large potential in relation to the status-quo - spread faster than small, incremental advances. A cultural disposition to accept innovation is required. A routine driven, closed and inertial milieu paralyses the dissemination of knowledge in all its levels and forms (Barata, 2004).

"Over the last twenty years there was a transformation identical to transformations that took three or four centuries, such as writing, the press and diffusion of the book. We are now fully into the digital revolution" (Nóvoa, 2013 p.12). This is accompanied by new political, social and cognitive mutations leading to new ways of being and knowing (Serres, $2012)^{6}$

\subsection{The end of century complexity}

The cultural complex of the late 2oth century is characterized by a syncretism where everything seems to be valid. Yet it contains within a world of uncertainty and complexity that induces a generalized feeling of insecurity. As a response to this state of affairs we witness the rise of fundamentalism and fanaticism. As always, throughout the history of ideas, we observe today a search for a coherent and meaningful view of society, of Man and its place in the World. At least two trends, attitudes or approaches embody the will to a unifying vision.

One of these trends rests on the belief that the homogenizing power of globalization 
and mass culture, combined with the globalization of information and business, will conduct to a cultural complex characterized by homogenization. The other trend is the refusal of submission to the legacy of positivism and cartesianism, and to the acceptance of complexity, unpredictability, emergence and dynamics as basic components of the operating logics capable of setting meaning and into the knowledge of the World.

Thus this area is better understood under a perspective that assumes the nature of «emergent» processes, of systemic complexity; of unpredictability and uncertainty.

\subsection{Questions at the dawn of the twenty-first century}

As implied in the introduction, the analysis exposed in this text aims at framing the interpretation of Design History and Design Studies within a cultural and civilisation complex in continuous mutation.

This approach, more than erudite exposition, was intended as a starting point to understand trends, and raise issues for debate.

The interpretation of trends, meanings and situations obtained at the close of the 2oth century, can only give rise to reflection, and to lead to new paths and perspectives.

Among these realities, we point out:

- The merging of the technologies of sound, image and data allowed by digital technology. The consequences of this fusion for professional and training practices are possibly huge?.

- The «portability» of access of visual and sound information, and the shifts in spatial scale and its perception.

- The rapid development of digital image and its integration with the real world, that while opening new areas to creativity create deontological, ethical and even juridical problems ${ }^{8}$.

This list of realities points to a situation where factual analysis, erudite, cartesian segmented will find itself insufficient to face change, uncertainty and dynamics. Approaches and mental posits based on probabilistic analysis of complexity will be increasingly necessary.

\footnotetext{
${ }^{8}$ While mass culture has a homogenising power it is the engine of individual affirmation. The search for recognition of the $\langle\langle\rangle\rangle$, the escape from anonymity, the search for fame - is often associated with copy and plagiarism and the search for «out of fashion» forms.
} 


\section{References}

Barata, José Pedro Martins (2004), As Ciências da Complexidade, Sinal ou Motor da Vontade de Unificação Cultural, Ciclo de Conferências - Espelhamento, Interrogação e Metamorfose, do Curso de Doutoramento de Base Curricular Universidade de Aveiro, Departamento de Didáctica e Tecnologia Educativa, Policopiado.

Fragoso, Margarida (2012), Design Gráfico em Portugal. Formas e Expressões da Cultura Visual do Século XX, Lisboa, Livros Horizonte.

Hobsbawn, Eric (2002), A Era dos Extremos, Lisboa, Editorial Presença.

Mumford, Lewis(1934), Technics and Civilization, New York, Harcourt, Brace.

Nóvoa, António Sampaio da (2013), "Um Olhar sobre a Educação" in Revista Descobrir,

Lisboa, Edição CML, pp. 21-24.

Serres, Michel (2012), Petite Poucette, Paris, Le Pommier.

Steiner, George (2006), A Ideia da Europa, Lisboa, Gradiva. 